\title{
NAS REDES ANTROPOLÓGICAS DA ESCOLA DE MANCHESTER: REMINISCÊNCIAS DE UM TRAJETO INTELECTUAL
}

\author{
Peter Fry ${ }^{1}$
}

A professora Cornelia Eckert me pediu reminiscências sobre a Escola de Manchester, ambientada no contexto britânico de minha formação. Devo começar, penso, no meu curso de graduação em Cambridge no início dos anos 1960.

Comecei estudando matemática, mas após um ano percebi que não tinha vocação para a disciplina. Embora gostasse da música de J.S. Bach, não compartilhava os outros gostos dos meus amigos matemáticos, como xadrez, por exemplo. Além disso, ansiava estudar uma ciência sobre a qual poderia me comunicar com os meus amigos e família. Talvez por conta de um professor da minha escola secundária que me dera, entre outros tantos livros para ler, A Deusa Branca de Robert Graves, optei pela antropologia. Achei ela ser uma ciência com tendências literárias! Como entrava no segundo ano do curso, especializando em antropologia social, perdi, infelizmente, a introdução à antropologia física e cultura material que era oferecida no primeiro ano.

O sistema de ensino em Cambridge era (e continua sendo) baseado em cursos formais dados por professores que falam durante cinqüenta minutos e saem sem mais nem menos. Há também encontros semanais com um tutor que providencia título e bibliografia para o ensaio da próxima semana. Ele lê os ensaios e comenta, engendrando uma conversa sobre as questões em pauta. Tive a sorte de ser tutorado por Jack Goody e sua então mulher Esther Newcomb Goody, ambos especialistas em África ocidental, Gana para ser exato.

Tanto nos tutoriais quando nos cursos formais não me lembro ter estudado nada mais avançado se não a estrutura e organização social de sociedades ditas primitivas. A única exceção foi o curso oferecido por Audrey Richards que naquela época estudava parentesco em aldeias perto de Cambridge e motivador de um dos meus ensaios sobre famílias matrifocais. A maravilhosa bibliografia incluía obras sobre Inglaterra (Young and Willmott 1957; Kerr 1958) e o Caribe (Smith 1956; Clarke 1957). Se não me engano, a lição era que matrifocalidade tinha a ver com posição de classe social e não

\footnotetext{
${ }^{1}$ Universidade Federal do Rio de Janeiro, Brasil.
} 
com cor, algo que espelhava (não sabia na época) a briga entre Franklin Frazier e Melville Herskovits, quando brigavam sobre a interpretação da família baiana na década de 1940 (Frazier 1943a; Frazier 1943b; Herskovits 1943). Ou seja, enquanto não havia nenhum preconceito contra a antropologia fora das sociedades ditas primitivas, as questões do dia, sobretudo a independências das antigas colônias britânicas eram assunto de conversa, mas não de estudo propriamente dito.

Quando me graduei, meu tutor Jack Goody sugeriu que fizesse pesquisa de campo. Ele consultou um jornal com dados sobre bolsas disponíveis e viu que havia Commonweatlh Scholarships (Bolsas da Comunidade Britânica) para a University College of Rhodesia and Nyassaland (UCRN) situado na capital da Rodésia do Sul, Salisbúria. Jack achava uma excelente opção, dado que o estabelecimento fazia parte da Universidade de Londres (na década de 1950 a Universidade de Londres era responsável pelo estabelecimento de "filiais" em algumas colônias britânicas) e que considerava o departamento de antropologia sob a batuta do Professor Clyde Mitchell de grande qualidade. Alem disso, concordamos que seria um imenso privilégio poder desenvolver um estudo etnográfico que perpassasse o momento de independência. A antiga Federação da África Central (Central African Federation) a derradeira tentativa de manter a hegemonia branca na África Central, tinha sido desmembrada em seus três países originais, um dos quais já independente (Maláui, antiga Nyassaland) e outro em processo de se tornar independente (Zâmbia, antiga Rodésia do Norte). Nós acreditávamos que a independência da Rodésia do Sul era apenas uma questão de tempo.

Me candidatei, sofri uma entrevista extenuante, ganhei a bolsa, me despedi dos meus amigos e família e apanhei um navio em Trieste (Itália) para aportar na cidade de Beira em Moçambique.

A viagem foi marcada por fortíssimas emoções na medida em que o frio de Trieste cedeu lugar ao calor de uma África que foi se revelando paulatinamente (uma visita a Cairo, paradas em Dar es Salaam e Mombasa). Foi nesta viagem que tive a oportunidade de conhecer os primeiros rodesianos brancos, um fazendeiro e sua senhora. Após saber que ia para a Rodésia, me perguntaram o que ia fazer. Expliquei que ia fazer pesquisa de campo antropológica numa aldeia qualquer. "Numa aldeia!" explodiu a senhora, "Isto não. Os nativos são sujos e desagradáveis. Não podemos admitir que seja possível, menos ainda aconselhável, um branco educado como você se sujeitar a um tormento desses. Melhor mesmo morar em Salisbúria. Mas você vai 
entender o que estamos dizendo após alguns meses no país." Era um refrão que ia ouvir repetida ad nauseam durante os próximos três anos na Rodésia.

Chegando na Beira, tomei o trem que atravessa Moçambique para Salisbúria (hoje Harare), capital da Rodésia do Sul (agora Zimbábue). Viajei na Primeira Classe, com cabine para dormir particular do lado de um carro restaurante com poltronas e cortinas de veludo cor de vinho. Jantei bem; com talheres pesados, pratos de porcelana e copos de cristal. Dormi pouco; a cabine se encheu de vaga-lumes. Na manhã seguinte, o trem subiu devagar para o planalto, parando perto de Umtali (agora Mutare), a primeira cidade de Rodésia, para que um outro trem, vindo em direção oposta, pudesse passar. Este também parou. Da minha janela olhei para a paisagem, e fui olhado por uma multidão de homens, crianças e mulheres negras, espremidos num carro de Quarta Classe, comendo fatias grossas de pão de forma e olhando para o jovem inglês tomando seu café de manhã britânico com bacon, ovos, torradas e geléia de laranja. Tinha chegado no mundo absurdo da desigualdade e segregação raciais, um mundo no qual ia passar os próximos anos da minha vida.

De Umtali para Salisbúria, o trem passou pelas melhores fazendas "brancas" do país, verdes nessa época das chuvas, os campos circundados por belas árvores misasa e midondo e repletos de tabaco e milho. De vez em quando, quebrando a monotonia da paisagem, surgia um ou outro amontoado de rochas cobertas de aloés, os famosos kopjes da Rodésia. Não vi nenhuma evidência de vida africana neste percurso. Os colonizadores brancos construíram suas estradas e caminhos de ferro para o escoamento dos produtos das grandes fazendas brancas, bem separadas das "Reservas Indígenas" demarcadas pela Lei de Alocação das Terras (Land Apportionment Act) de 1933.

$\mathrm{Na}$ chegada a Salisbúria fui levado à UCRN e instalado num quarto de estudante. A UCRN era o único lugar do país onde negros e brancos podiam morar juntos nesse país racialmente segregado nos moldes da apartheid da África do Sul. Os professores eram quase todos britânicos. Embora a UCRN tivesse autonomia administrativa e curricular, não conferia graus acadêmicos. Isto era prerrogativa da Universidade de Londres. A Rodésia branca, obcecada pela manutenção dos "padrões cristãos civilizados", precisava deste carimbo de excelência. Seguindo esta lógica ganhei dois orientadores, Clyde Mitchell na UCRN e Mary Douglas de University College London (UCL).

Ao mesmo tempo em que a UCRN era o grande orgulho era também o maior embaraço dos governantes brancos da Rodésia, pois tinha se tornado o mais estridente 
foco de oposição ao governo racista do país. Situada no bairro mais alto da cidade, ficou conhecida como "O Kremlin no Morro". Dentro da Universidade o departamento que mais articulava a oposição ao governo foi o de Estudos Africanos (não se chamava Antropologia porque naquela época de descolonização a Antropologia tinha se tornado uma disciplina não grata!), onde professores e alunos usavam de sua teoria e seu conhecimento do país para escrever artigos e proferir palestras contra a iniquidade da segregação racial e a favor da urgente independência do país com regime de sufrágio universal.

O Departamento era liderado por Clyde Mitchell. Outro professor de muita influência sobre todos nós foi Jaap van Velsen. Ex-maquis da Holanda, alto e rude, Jaap tinha talvez a voz mais alta na luta política contra o racismo e o colonialismo. Em 1966, ele seria expulso do país pelas suas posições críticas. Semanas mais tarde seria acusado de ser membro de um grupo envolvido na guerrilha urbana num processo movido contra outro professor da universidade. Jaap insistiu que o trabalho acadêmico devia refletir as preocupações de todos nós com o crescimento do partido racista, a Frente Rodesiana, sob a liderança de Ian Smith e a atuação dos partidos nacionalistas, A União Zimbabuana do Povo Africano (ZAPU) e a União Africana Nacional Zimbabuana (ZANU). Mas, mais de que isso insistiu que não nos envolvêssemos diretamente com os movimentos de libertação nacional. Argumentou que em situações de confronto radical, as fronteiras entre os dois lados não deveriam ser borradas. Para justificar sua posição lembrou a sua própria experiência na resistência holandesa durante a Segunda Guerra Mundial. Como maquis, ele teve que deserdar seus parentes e amigos na Alemanha. Se tivesse que matá-los, mataria! Disse-me que se eu tivesse vontade de contribuir para o fim do colonialismo e racismo eu devia fazer tudo para influenciar os meus pares. Até hoje tenho uma forte desconfiança dos antropólogos e missionários em geral que alegam terem se incorporados aos grupos indígenas a ponto de reivindicarem um parentesco quase verdadeiro, e, conseqüentemente, o direito de falar em nome deles.

Clyde Mitchell e Jaap van Velsen foram respectivamente colaborador e aluno do antropólogo sul africano Max Gluckman, que na época dirigia o Departamento de Antropologia na Universidade de Manchester. Jaap tomou a dianteira das críticas, me acusando de ter tido uma educação totalmente ultrapassada num departamento que pouco interesse tinha pelas condições contemporâneas das sociedades que estudavam. Me acusou de ser "effete" que quer dizer uma mistura de fraco, sem poder, e talvez 
afeminado! A crítica também era contra um excesso de "culturalismo" que negava aos sujeitos africanos a liberdade de tomar decisões racionais de acordo com as situações em que se encontraram. No fundo, é claro, a crítica derivava dos conflitos no campo da antropologia britânica da época. Para me resgatar seria necessária uma "conversão" aos preceitos da "Escola de Manchester" antes de definir o meu objeto de estudo. Me deu para ler o texto base da tal Escola de Manchester, o artigo heróico de Gluckman, Análise de uma situação social na Zululândia moderna, publicado originalmente em 1940 (Gluckman, 1940) e presente no Brasil numa importante coletânea organizada por Bela Feldman Bianco (Feldman-Bianco, 2010). Nele, eu deveria achar uma ferramenta poderosa de análise de situações de mudança rápida. A idéia era simples: que o pesquisador deveria apresentar o seu material de observação de situações sociais ou séries de situações, a partir das quais indagaria questões merecedoras de análise. Chamado de análise situacional ou o método de casos estendidos ou detalhados (extended case method), propunha-se tirar a Antropologia da análise das normas e valores para concentrar na vida social "real" na qual as normas e valores, frequentemente contraditórios entre si, seriam utilizados de acordo com a racionalidade do agente social em situações sociais concretas. Jaap van Velsen, no seu artigo sobre esse método (van Velsen 1967) — traduzido e publicado no livro de Bela Feldman Bianco (Feldman-Bianco 2010) — nota que o material de pesquisa que era antes utilizado como "apta ilustração" de modelos abstratos desenvolvidos pelo etnógrafo, seria agora o ponto de partida da argumentação. A noção de situação nos permitia entender os seres humanos como infinitamente adaptáveis às múltiplas situações onde se encontrassem. A própria noção de identidade era situacional. Nada estranho, portanto, um africano ser piloto de avião numa situação e chefe tribal em outra. Para nós, o conceito de "raça" como de "tribo" teria que ser banido do arsenal teórico e entendido como conceito ideológico da maior periculosidade. A nossa antropologia hoje em dia se chamaria de anti-essencialista.

Se na acepção de Jaap van Velsen, Manchester se opunha a Cambridge (e Oxford, também, onde ele começou os seus estudos de antropologia) Lyn Schumaker (Schumaker, 2001) argumenta e com razão que a antropologia que mais tarde chamarse-ia de Escola de Manchester, originou no Instituto Rhodes Livingstone na antiga Rodésia do Norte (agora Zâmbia), onde um grupo de antropólogos de origem sul africana se juntou ao Max Gluckman em oposição à antropologia oficial do apartheid sul-africano, a escola volkekunde, com sua ênfase na natureza de determinados povos 
(volk), cada qual com a sua cultura específica. Rejeitando tais interpretações que denominaram "culturalistas", e ao mesmo tempo a interpretação da mudança cultural de Bronislaw Malinowski, que imaginava culturas em contato umas com as outras, insistiram na importância de considerar o encontro entre pessoas e grupos em situações concretas. Tratava-se da pesquisa de campo, e de novo em oposição aos volkekundiges, que favorecia a presença dos africanos em entrevistas formais. Eles admiraram Malinowski, levando a sua doutrina de observação participante a algumas conseqüências bastante elegantes. Assim, Gluckman desenvolveu a sua primeira pesquisa entre os Zulu vestido em roupas africanas tradicionais. Dizem que Jaap van Velsen costumava andar vestido em sacos de cimento durante a sua pesquisa entre os Tonga de Malaui. Schumaker argumenta que todos foram encorajados a dançar (literalmente) para ganhar o coração e as mentes das pessoas que estudaram. De fato, minhas persistentes tentativas de seguir a coreografia africana resultaram em dores de coluna até hoje. Quando Max Gluckman foi para Manchester ele promoveu um estilo "classe operária" com visitas aos bares perto da universidade e às vezes seminários no estádio de Manchester United. A mulher de um dos pesquisadores falava para Schumaker que preferia visitar uma fábrica de aço a ir ao balé! ${ }^{1}$

Olhando para trás, vejo o quanto que esta perspectiva da antropologia de Gluckman e seus seguidores estava fortemente relacionada à sua posição política contra o colonialismo e o racismo, quase um "charter" no sentido Malinowskiano. Defendia a igualdade de direitos sociais e políticos dos africanos contra os argumentos ora biologizantes ou culturalistas do governo colonial. A nossa pesquisa de campo, malinowskiana ao extremo, era entre outras coisas um statement da nossa igualdade para com as pessoas que pesquisávamos, mesmo se estes freqüentemente interpretavam o nosso comportamento como na melhor das hipóteses maluco e na pior, um investimento num futuro de poder e riqueza! As duas posições tinham um bocado de razão.

Embora Max Gluckman tivesse falado muito de "costumes", os seus textos privilegiavam a autonomia do indivíduo para escolher o seu modo de vida, legitimandoo com os valores adequados disponíveis. Desta forma, se defendia a idéia que um cidadão africano era ao mesmo tempo um membro de um grupo tribal e partícipe da economia e política nacionais. Os conceitos de des-tribalização e aculturação eram anátema, já que partiram do princípio que o contato com os europeus, a industrialização e a vida urbana levava necessariamente ao abandono da cultura local rumo a cultural 
considerada dominante. A defasagem política e econômica entre os africanos e europeus, dessa perspectiva, resultava da dominação colonial, e da privação de oportunidades. Nossa antropologia inspirava e legitimava a nossa postura política contra o colonialismo e a discriminação racial, a favor da democracia e a extensão do sufrágio e das oportunidades de educação e de emprego para todos. Afinal, lutávamos contra aqueles que acreditavam que os Africanos eram, ou inerentemente, ou por causa do "atraso cultural", incapazes de participar plenamente no "mundo dos brancos" e, mais ainda, de gerir um governo e uma economia nacionais. Mas também reconhecemos o direito dos africanos de manter em paralelo formas de vida social derivadas da sua tradição pré-colonial.

Após o rito de passagem de Cambridge para Manchester, ficou decidido que eu pesquisaria um fenômeno absolutamente fundamental na África central, a migração para as cidades e a relação entre cidade e campo. A idéia era que ficaria um ano numa zona rural conhecendo as famílias com um ou mais membros na cidade de Salisbúria. Passaria o segundo ano com este pessoal na cidade, assim vendo a questão de ambos os lados. Combinava perfeitamente com os interesses dos meus professores cujo interesse maior era de fato a relação entre a "modernidade" e as formas tradicionais. Escolhi uma "reserva tribal" uns 80 quilômetros da capital.

A minha pesquisa de campo coincidiu com o crescimento dos movimentos africanos nacionalistas e da determinação da maioria dos brancos a não ceder. $\mathrm{Na}$ medida em que Ian Smith e sua Frente Rodesiana se fortaleciam no poder, os dois partidos nacionalistas incrementavam seus protestos violentos. Mas também lutavam entre si para ganhar o apoio da população negra. Membros da ZAPU sofreram ataques constantes dos membros da ZANU, e vice-versa. Eu ficava numa situação bastante constrangedora, pois além da desconfiança das autoridades brancas (a maioria compartilhava as opiniões do casal no navio), alguns membros da ZAPU e da ZANU desconfiavam que eu pertencia ao partido oposto, enquanto outros imaginavam que era espião do governo de Smith.

A tática que adotei, então, foi de ficar quieto na aldeia do meu intérprete, Kenneth Mupanduki, observando o que podia observar, aprendendo a língua, aceitando quaisquer convites para casamentos, funerais, mutirões, etc, e tentando ser o mais gentil possível, levando senhoras grávidas para a clínica e coisas do gênero. Acima de tudo, procurei observar situações concretas. Em retrospecto, creio que estes meses de semiinvisibilidade foram fundamentais, pois por um processo mais de osmose do que de 
aprendizagem formal me tornei razoavelmente "competente" na cultura e língua Shona. Lembro-me até hoje da alegria que senti quando pude rir de verdade de uma piada contada em Chishona! Aprendi também a sentir os efeitos do racismo exercido contra os meus vizinhos. Vivia quase sempre deprimido; a revolta contra o colonialismo aumentou cada dia mais e, para tornar pior a situação, as minhas notas de campo não tinham nenhum fio condutor e nenhuma consistência. Pareciam um amontoado de observações desconexas, totalmente inadequadas para a formulação de uma tese qualquer, sobretudo uma tese "Manchesteriana."

Tudo mudou com algumas transformações dramáticas no comportamento de Kenneth Mupanduki. Aos poucos desenvolveu uma série de "alergias", primeiro a pão branco e café, depois à cerveja, fumo de cigarro e o alimento básico de Rodésia, sadza, uma espécie de polenta grossa feita de fubá. Estas proibições alimentares tiveram o efeito de por Kenneth aparte da vida em comum e de mim em particular. A causa das "alergias", revelada por um adivinho importante, era que Kenneth estaria sendo escolhido para ser médium de um ou mais importantes antepassados. Acompanhando Kenneth no seu périplo à busca da "cura" tive forçosamente de encontrar muitos médiuns e a multidão de gente que os consultava para a cura dos seus males. Todo um lado da sociedade até então invisível foi se revelando. Ficou cada vez mais evidente que a prática religiosa não era absolutamente "assunto de antropólogo tradicional", mas sim elemento vital para o povo de Chiota. Após anos de repressão por parte dos missionários, a possessão por espíritos estava mais uma vez florescente em Chiota e, mais importante ainda, havia uma participação maciça de jovens com um certo grau de educação formal como Kenneth. Logo percebi que estava em curso um movimento social de volta ao passado, de nacionalismo cultural, estritamente relacionado com a situação política do país. Nestas alturas tanto ZAPU como ZANU tinham sido banidas. Reuniões políticas de todo tipo eram proibidas também. O foco da discussão política tinha deslizado para a semi-clandestinidade dos rituais de possessão. Resolvi escrever sobre religião e política.

Apresentei os meus dados na série de seminários de pesquisa do departamento e recebi a luz verde para prosseguir. Tive o azar de não conseguir colher informações detalhadas sobre a migração rural-urbana, mapeando as redes sociais das pessoas de Chiota. Mas tinha conseguido aquilo que era também muito valorizado na noção de pesquisa de campo: a descoberta de algo antes desconhecido. E tinha boas notas de 
campo sobre a família de meu assistente e de um médium importantíssimo com quem morei durante seis meses.

Esta série de seminários merece uma pequena reflexão. Com uma certa regularidade, nós pesquisadores jovens voltávamos para a universidade especialmente para apresentar os nossos dados, ouvir os dos outros e sofrer as intervenções cruelmente diretas dos nossos professores. Jaap van Velsen era especialmente duro nas suas criticas alegando que se baseava no procedimento de Gluckman que encorajava a crítica mais direta possível durante o seminário para em seguida tratar quaisquer feridas com atividades de convívio social, uma cerveja no bar ou assistir a um jogo de futebol de Manchester United (parte da comunhão com a classe operária observada por Schumaker). O pior momento que lembro foi depois de um seminário apresentado por um colega meu quando, após o silenciozinho de praxe, Jaap perguntou laconicamente: “E daí?" O apresentador não se desmontou e tomamos a cerveja ritual em seguida num clima de confraternização sem maiores problemas. Penso até hoje que este procedimento é a melhor maneira de lidar com a produção acadêmica. Difícil, porém, de fazer no Brasil onde temos o costume de interpretar as críticas como ataques morais ad hominem ou ad mulierem contra as nossas pessoas, motivadas apenas por dissabores ou competitividade! No Brasil, suspeito, a crítica de colegas e amigos quase sempre se dá na surdina dos comentários privados. Evita-se o confronto direto; o que é bom para preservar a aparente cordialidade das relações de trabalho, mas que é ruim pelo clima de suspeitas e paranóia que engendra. Prefiro saber onde piso, ou "where I stand", como dizem os ingleses. Tanto é que vale dizer que Jaap van Velsen se tornou mentor e amigo até a sua morte precoce em 1990.

Foi ao longo desses seminários que Clyde Mitchell foi desenvolvendo o seu trabalho sobre redes sociais. Mitchell escreveu a sua primeira monografia sobre a organização social dos Yao em Malaui. Junto com outros trabalhos (Victor Turner sobre os Ndembu, por exemplo) fez uma importantíssima contribuição à antropologia da África central. Publicou com Max Gluckman e John Barnes, em 1949 um artigo seminal sobre as relações entre as sociedades africanas e a administração colonial onde desenvolveu o conceito de "papel intercalado" (intercalary role) para caracterizar o papel dos chefes de aldeias que mediaram a ordem local e a administração central, representando o primeiro perante o segundo e vice-versa (Gluckman, Mitchell et al. 1949) . E, em 1959, escreveu um dos meus ensaios antropológicos favoritos, The Kalela Dance, (Mitchell 1959), que aparece traduzido no livro da Bela Feldman Bianco (2010). 
Trata-se de um ensaio na tradição da análise situacional de Gluckman, dessa vez sobre uma dança do povo Bisa nas cidades de Zâmbia. Observando o paradoxo dos dançarinos desta dança "tribal" dançarem com roupa tipicamente européia com cada membro adotando um papel dentro do mundo dos brancos, Mitchell desenvolve uma fina análise sobre a significação de raça e origem étnica na vida social dessas cidades. Mas enquanto a análise parte de um relato etnográfico (o que Clifford Geertz mais tarde chamaria de descrição densa, imagino), Mitchell traz dados quantitativos que colheu durante um survey sobre atitudes das pessoas com relação aos demais grupos étnicos na cidade.

Para efetuar as suas análises quantitativas ele instalou na Universidade de Salisbúria uma imensa máquina Hollerith, uma espécie de proto- computador, que computava as relações entre as muitas variáveis a partir da leitura mecânica de cartões perfuradas. Em seguida, ainda no intuito de melhor entender a organização social dos migrantes para a cidade se empenhou na elaboração de uma teoria de redes sociais. Construindo sobre os trabalhos anteriores de J. A. Barnes, ele estava convencido que a antropologia precisava de uma ferramenta para o estudo das relações sociais nas cidades onde o parentesco não era mais dominante como teria sido (em princípio) nas sociedades rurais pré-industriais. Entre os jovens pesquisadores da época foi Bruce Kapferer que mais contribuiu para a teoria das redes sociais na sua análise das relações sociais numa fábrica de cobre em Zâmbia. Expus os seus achados no nosso seminário, publicando os resultados finais em 1972 (Kapferer, 1972). Os resultados do trabalho de Mitchell saíram em 1969 (Mitchell, 1969). Neste livro aparece também um importante artigo de Barnes (Barnes, 1969) que aparece traduzido na coletânea de Bela FeldmanBianco (2010).

Em novembro de 1965, Ian Smith unilateralmente declarou Rodésia independente da Grã Bretanha. Concomitantemente pôs em marcha uma política de repressão cada vez mais rigorosa ao movimento negro nacionalista. Em agosto do ano seguinte Jaap van Velsen foi expulso do país junto com alguns outros professores da Universidade. Em dezembro eu saí da Rodésia com dois outros professores universitários. De Landrover, viajamos à Inglaterra via Botsuana, Namíbia, Angola, Nigéria, Níger, Argélia, Espanha e França. Ao convite de Mary Douglas, comecei a minha carreira acadêmica como professor assistente no Departamento de Antropologia de University College, Londres. 
Em 1969 defendi a minha tese de doutorado que defini como pré- e pósManchester (Fry, 1976). A primeira parte, que chamei de pré-Manchester, descreve a área onde trabalhei e expõe o sistema de crenças em volta da possessão por espíritos de várias ordens. A segunda parte se baseia num caso estendido (extended case) que são os eventos que seguiram a mediunidade de Kenneth Mupanduki mostrando como os espíritos atuavam politicamente em todas as esferas da vida cotidiana, inclusive na luta contra o colonialismo e o racismo. Kenneth e seus amigos médiuns disseminaram a consciência de que Jesus Cristo era apenas um espírito ancestral poderoso dos brancos. Ademais uma volta aos antepassados era necessária para a libertação do domínio colonial. Mais tarde, um outro antropólogo ia demonstrar o papel que certos médiuns de fato desempenharam na guerra para independência (Lan, 1985). Assim, tentei basear a minha análise em dados de campo sem utilizá-los como "mera ilustração" da estrutura social. Pretendi, dessa forma, seguir os preceitos dos meus novos mestres, sem abandonar os antigos!

Quais as lições que permaneceram comigo esses anos todos?

Evidentemente muita coisa aconteceu na antropologia nos anos que seguiram os escritos de Gluckman, Mitchell, van Velsen e outros membros da escola de Manchester. Mas a abordagem geral e o método do estudo de situações e casos estendidos não perderam a sua importância. Entrevistas gravadas são importantes, sem dúvida, mas não representam exatamente a vida como ela é vivida normalmente! Às vezes têm até aços da volkekunde. A não ser que se trate de um grupo qualquer que passa boa parte do seu tempo sendo entrevistados por antropólogos. Tenho observado entre alunos meus, um certo medo de utilizar as suas observações, como se fossem menos "objetivas", menos “científicas", menos "comprováveis" que as impressões digitais nos CDs e DVDs. O que as pessoas fazem e dizem em situações sociais que podemos observar valem, do meu ponto de vista, muito mais que entrevistas formais, que tendem a apanhar posições normativas. Observando várias situações, como pregava Gluckman, é uma maneira interessante de tentar apanhar o máximo possível do processo social e de poder se aproximar a uma análise mais fina da relação entre ação e representação.

Mas a análise situacional tem uma outra vantagem, a de ordenar a descrição e análise, um "truque de escrita" como me disse certa vez Carlos Vogt. Um dos grandes problemas da análise antropológica é de saber onde começar e onde terminar, já que tudo que estudamos é entrelaçado com todo o resto. Situações sociais, como a abertura da ponte do trabalho fundador de Gluckman e a dança urbana do Mitchell, tem um 
início, meio e fim. Começando dessa maneira, descrevendo o desenrolar de uma situação, é possível logo em seguida arrolar as questões teóricas que podem ser examinados detidamente em capítulos posteriores. Uma outra vantagem dessa forma de organizar um texto é que o leitor logo se torna familiar com o material a ser analisado, facilitando a sua compreensão da análise que segue. Jaap van Velsen argumentou que este método é mais honesto que outros métodos uma vez que o leitor teria a mão todos os dados brutos, posicionado assim para poder questionar a análise do autor, e propor novas interpretações. Tem um grão de verdade. Mas sabemos perfeitamente após tanta crítica das velhas monografias que a própria escrita das situações é sempre parcial. Mas, digamos, o reconhecimento da parcialidade, o reconhecimento de que o ponto de vista de um nativo é representado pelo ponto de vista de outro que se apresenta como antropólogo, é mais um passo importante para que o leitor possa saber melhor com quem está falando.

Finalmente, fico imaginando se a escola de Manchester tivesse chegado com força junto com o Departamento de Antropologia da Universidade de Harvard na fundação da moderna antropologia social brasileira. Teria sido uma ferramenta poderosa para ajudar Roberto Cardoso de Oliveira no desenvolvimento dos seus estudos sobre a inter-ação entre os índios e a sociedade envolvente. Até hoje, penso que as análises feitas nas cidades da África central seriam utilíssimas para compreender as múltiplas identidades abertas para os índios, enterrando por vez a antropologia e política indigenista brasileiras antigas que operavam, ambas, com o conceito de aculturação, como que abrissem apenas duas perspectivas para os índios: assimilando-se à sociedade nacional ou mantendo a sua identidade étnica. Até hoje, suspeito que o conceito de "índio aldeiado", contem um pouco essa ideia, transmitindo a noção de que quem habita uma aldeia é mais "autenticamente" índio que quem vive nas cidades. Bobagem! A escola de Manchester percebeu claramente que aldeias e cidades são situações, seus habitantes sempre passageiros e identidades situacionalmente invocadas. Para Gluckman e seus colaboradores, não havia nada de esdrúxulo em encontrar um africano líder do seu sindicato e ao mesmo tempo adivinho, por exemplo.

É na antropologia nas cidades então que as lições da Escola de Manchester continuam vivas, com a sua ênfase na pesquisa de campo baseada na participação plena com o intuito de entender melhor a inserção social complexa dos indivíduos de situação em situação. 


\section{Referências}

BARNES, J. A. "Networks and Political Process Social Networks". In: J. C. Mitchell (ed.) Urban Situations: Analysis of Personal Relationships in Central African Towns. Manchester: Manchester University Press, 1969. p. 51-76.

CLARKE, E. My Mother who Fathered Me: A Study of the Family in Three Selected Communities in Jamaica. London: Allen and Unwin, 1957.

FELDMAN-BIANCO, B. O. Antropologia das sociedades contemporâneas: métodos. São Paulo: Editora Unesp, 2010.

FRAZIER, E. F. "Rejoinder by E. Franklin Frazier". In: American Sociological Review, vol. 8 (1-6), 1943a. p. 402-404.

FRAZIER, F. "The negro family in Bahia, Brazil". In: American Sociological Review, vol. 7, no 4, 1943b. p. 465-478.

FRY, P. Spirits of Protest: Spirit-Mediums and the Articulation of Consensus Among the Zezuru of Southern Rhodesia (Zimbabwe). Cambridge: Cambridge University Press, 1976.

GLUCKMAN, M. "Analysis of a Social Situation in Modern Zululand". In: Bantu Studies 14, 1940. p. 1-30.

GLUCKMAN, M., J. C. Mitchell, et al. "The Village Headman in British Central Africa." In: Africa: Journal of the International African Institute, vol. 19, no 2, 1949. p.89-106.

HERSKOVITS, M. "The Negro in Bahia, Brazil a problem in method". In: American Sociological Review, vol. 8, n 4, 1943. p. 394-402.

KAPFERER, B. Strategy and Transaction in an African Factory: African Workers and Indian Management in Zambian Town. Manchester: Manchester University Press, 1972. KERR, M. The People of Ship Street: On a Liverpoool Slum. London: Routledge \& Kegan Paul, 1958.

LAN, D. Guns \& Rain: Guerrillas \& Spirit Mediums in Zimbabwe. Harare: Zimbabwe Publishing House, 1985.

MITCHELL, J. C. The Kalela dance: aspects of social relationships among urban africans in Northern Rhodesia. Manchester: Manchester University, 1959.

MITCHELL, J. C. Social Networks in Urban Situations: Analysis of Personal Relationships in Central African Towns. Manchester: Manchester University Press, 1969.

SCHUMAKER, L. Africanizing Anthropology: Fieldwork, Networks and the Making of Cultural Knowledge in Central Africa. Durham and London: Duke University Press, 2001.

SMITH, R. T. The Negro Family in British Guiana. London: Routledge and Paul, 1956.

VAN VELSEN, J. The Extended-Case Method and Situational Analysis. In: A. L. Epstein (ed.) The Craft of Social Anthropology. London: Tacistock, 1967. p. 129-149.

YOUNG, M. D. and P. Willmott. Family and Kinship in East London. London: Routledge \& Kegan Paul, 1957. 